\title{
Article
}

\section{Effects of footwear variations on three- dimensional kinematics and tibial accelerations of specific movements in American football}

Sinclair, Jonathan Kenneth, Rooney, Elliot, Naemi, Roozbeh, Chockalingam, Nachi and Atkins, Stephen

Available at http://clok.uclan.ac.uk/14519/

Sinclair, Jonathan Kenneth ORCID: 0000-0002-2231-3732, Rooney, Elliot, Naemi, Roozbeh, Chockalingam, Nachi and Atkins, Stephen (2017) Effects of footwear variations on three-dimensional kinematics and tibial accelerations of specific movements in American football. Journal of Mechanics in Medicine and Biology, 17 (2). ISSN 0219-5194

It is advisable to refer to the publisher's version if you intend to cite from the work. http://dx.doi.org/10.1142/S0219519417500269

For more information about UCLan's research in this area go to http://www.uclan.ac.uk/researchgroups/ and search for < name of research Group>.

For information about Research generally at UCLan please go to http://www.uclan.ac.uk/research/

All outputs in CLoK are protected by Intellectual Property Rights law, including Copyright law. Copyright, IPR and Moral Rights for the works on this site are retained by the individual authors and/or other copyright owners. Terms and conditions for use of this material are defined in the policies page. 
AQ: Please provide complete affiliation for Naemi R.

\title{
EFFECTS OF FOOTWEAR VARIATIONS ON THREE-DIMENSIONAL KINEMATICS AND TIBIAL ACCELERATIONS OF SPECIFIC MOVEMENTS IN AMERICAN FOOTBALL
}

\author{
SINCLAIR $\mathrm{J}^{* \star \star}$, ROONEY E*, NAEMI R, ATKINS S* \\ and CHOCKALINGAM $\mathrm{N}^{\dagger}$ \\ *Division of Sport Exercise and Nutritional Sciences \\ School of Sport Tourism and Outdoors \\ University of Central Lancashire UK \\ ${ }^{\dagger}$ Faculty of Health Sciences, Staffordshire University \\ College Road, Stoke-on-Trent, Staffordshire ST4 2DE, UK \\ ॠksinclair@uclan.ac.uk \\ Received 19 November 2014 \\ Accepted 20 March 2016
} Published

\begin{abstract}
American football is associated with a high rate of non-contact chronic injuries. Players are able to select from both high and low cut footwear. The aim of the current investigation was to examine the influence of high and low cut American football specific footwear on tibial accelerations and three-dimensional (3D) kinematics during three sport specific movements. Twelve male American football players performed three movements, run, cut and vertical jump whilst wearing both low and high cut footwear. 3D kinematics of the lower extremities were measured using an eight-camera motion analysis system alongside tibial acceleration parameters which were obtained using a shank mounted accelerometer. Tibial acceleration and 3D kinematic differences between the different footwear were examined using either repeated measures or Friedman's ANOVA. Tibial accelerations were significantly greater in the low cut footwear in comparison to the high cut footwear for the run and cut movements. In addition, peak ankle eversion and tibial internal rotation parameters were shown to be significantly greater in the low cut footwear in the running and cutting movement conditions. The current study indicates that the utilization of low cut American football footwear for training/performance may place American footballers at increased risk from chronic injuries.
\end{abstract}

Keywords: American football; footwear; chronic injuries; lower extremity; biomechanics.

\section{Introduction}

American football is one of the world's most popular sports, particularly in North America and Canada although a strong following and professional structure now also exists in Europe. Currently, over one million high school and 70000 college athletes take part in this sport annually in the USA. ${ }^{1}$

$\$$ Corresponding author. 


\section{J. Sinclair et al.}

American football is known to be associated with a high rate of lower extremity injuries when compared to other team-based sports. ${ }^{2}$ Aetiological work has demonstrated that in excess of $61 \%$ of athletes will suffer from an injury over the course of one playing season. ${ }^{3}$ Although American football is recognized as a high contact sport, $25-36 \%$ of all reported injuries have been demonstrated as non-contact in nature. ${ }^{1}$ Injuries to the lower extremity are the most prevalent in American football, with injuries to the ankle and knee joint being the most common. ${ }^{4,5}$

It has been recognized that one of the key mechanisms by which non-contact American football injuries occur, is the interaction between the shoe and surface. ${ }^{6}$

In a number of studies, the effects of different American football surface conditions on the biomechanical mechanisms linked to the aetiology of injury have been investigated. ${ }^{7-10}$ However, despite being potentially important in terms of the mechanisms by which lower extremity injuries are considered to occur, there is currently a paucity of research concerning American football specific footwear. American football footwear are specifically designed to use in a game of American football footwear and feature cleated outsoles which serve the purpose of enhancing traction on the synthetic surfaces that American football is typically played on. ${ }^{11}$ American football players are able to select from both high and low cut footwear for their training and performance requirements. High and low cut footwear are typically designed for different playing positions. Running backs and wide receivers typically utilize low cut footwear, whilst tackles, guards and linebackers typically select higher cut footwear. ${ }^{12}$ Low cut footwear have a lower mass, whereas higher cut footwear are heavier but provide additional support. ${ }^{12}$ Although the effects of high and low cut footwear in other sports have been investigated previously, ${ }^{13-15}$ these effects have not been examined in American football.

There is a clear lack of published work investigating the effects of different footwear on the parameters linked to the aetiology of injury development in American footballers. Currently, both high and low cut shoes are utilized for American football performance, yet there is no published information regarding the 3D kinematic and tibial acceleration parameters linked to the aetiology of lower extremity injuries. Therefore, the aim of the current investigation was to examine the influence of high and low cut American football specific footwear on the 3D kinematics and tibial accelerations of three sport specific movements. An investigation of this nature can provide players with information regarding selection of appropriate footwear, which may help to attenuate the high incidence of lower extremity injuries in this sport.

\section{Methods}

\subsection{Participants}

Twelve experienced university first team level male American football players took part in the current investigation. All participants habitually wore low cut footwear 
and played at "offense" positions, which included wide receiver, running back, quarter back, offensive tackle and tight end. All were free from lower extremity injuries at the time of data collection and provided written informed consent. The Mean ( \pm Standard Deviation) anthropometric characteristics of the participants were: Age $=22.47( \pm 1.13)$ years, Height $=1.77( \pm 0.08) \mathrm{m}$, Mass $=80.32( \pm 6.33) \mathrm{kg}$. Ethical approval was sought and granted by the University Ethics Committee for the procedure utilized in this investigation.

\subsection{Procedure}

Participants completed five trials of three movements specific to American football; run, cut and vertical jump in both footwear conditions. These movements were selected based on previous recommendations as being fundamental to most sports. ${ }^{16}$ Participants performed their trials on a synthetic grass surface which overlaid the laboratory floor. Kinematics and tibial acceleration data were collected synchronously using an analogue to digital interface board (Qualisys Medical AB, Goteburg, Sweden). Kinematic information was obtained from the lower extremities using an eight camera optoelectronic motion capture system (Qualisys Medical AB, Goteburg, Sweden) using a capture frequency of $250 \mathrm{~Hz}$. Dynamic calibration of the camera system was performed before each data collection session. To control for any order effects the order in which participants performed in each footwear and movement condition was randomized. As ground reaction force information was not available, the stance phase for running and cutting trials and the impact phase for jumping trials were determined using kinematic information.

A uni-axial (Biometrics ACL 300, Cwmfelinfach, Gwent United Kingdom) accelerometer which collected data at $1000 \mathrm{~Hz}$ was used to measure vertical accelerations at the tibia. The accelerometer was positioned onto a piece of carbon-fiber in accordance with the protocol used by Sinclair et al. ${ }^{17}$ The device was mounted to the anterio-medial aspect of the tibia, $0.08 \mathrm{~m}$ above the malleolus. This location served to decrease the influence that sagittal plane motion about the ankle can have on the acceleration signal. ${ }^{18}$ To reduce the influence of movement artifact a strong adhesive tape was placed over the device and the lower leg.

To quantify lower extremity joint kinematics in all three planes of rotation, the calibrated anatomical systems technique ${ }^{19}$ was utilized. Retroreflective markers $(19 \mathrm{~mm})$ were positioned unilaterally allowing the right; foot, shank and thigh to be defined. The foot was defined via the first and fifth metatarsal heads, medial and lateral malleoli and tracked using the calcaneus, first metatarsal and fifth metatarsal heads. ${ }^{20}$ The shank was defined via the medial and lateral malleoli and medial and lateral femoral epicondyles and tracked using a cluster positioned onto the shank. ${ }^{21}$ The thigh was defined via the medial and lateral femoral epicondyles and the hip joint center and tracked using a cluster positioned onto the thigh. ${ }^{21}$ To define the pelvis, additional markers were positioned onto the anterior (ASIS) and posterior (PSIS) superior iliac spines and this segment was tracked using the same 


\section{J. Sinclair et al.}

markers. The hip joint center was determined using a regression equation that uses the positions of the ASIS markers. ${ }^{22}$ The centers of the ankle and knee joints were delineated as the mid-point between the malleoli and femoral epicondyle markers. ${ }^{21,23}$ Each tracking cluster comprised four retroreflective markers mounted onto a thin sheath of lightweight carbon-fiber with length to width ratios in accordance with Cappozzo et al. ${ }^{24}$ Static calibration trials were obtained allowing for the anatomical markers to be referenced in relation to the tracking markers/clusters. The $Z$-(transverse) axis was oriented vertically from the distal segment end to the proximal segment end. The $Y$-(coronal) axis was oriented in the segment from posterior to anterior. Finally, the $X$-(sagittal) axis orientation was determined using the right hand rule and was oriented from medial to lateral. All retroreflective markers were positioned via manual palpation by the lead author.

Data were collected during run, cut and jump movements as follows:

\subsection{Run}

Participants ran at $40 \mathrm{~m} \cdot \mathrm{s}^{-1} \pm 5 \%$, running velocity was monitored using infra-red timing gates (SmartSpeed Ltd. UK). Footstrike was determined as the point at which the vertical velocity of the calcaneus marker changed from negative to positive and toe-off was delineated using the second instance of peak knee extension. ${ }^{25}$

\subsection{Cut}

Participants completed $45^{\circ}$ sideways cut movements using an approach velocity of $4.0 \mathrm{~m} \cdot \mathrm{s}^{-1} \pm 5 \%$. Cut angles were defined using masking tape so that it was clearly evident to participants. ${ }^{26}$ Once again, footstrike was delineated as the point at which the vertical velocity of the calcaneus marker changed from negative to positive and toe-off was delineated using the second instance of peak knee extension. ${ }^{25}$

\subsection{Jump}

Participants completed counter movement vertical jumps in which they were required to use full arm swing. The impact phase of the jump movement was quantified and was considered to have begun when the vertical velocity of the metatarsal markers changed from negative to positive and ended at the point of maximum knee flexion. ${ }^{27}$

\subsection{Experimental footwear}

The footwear used during this study consisted first of a high cut shoe (Nike Lunar code pro) that have a seven cleat outsole and a mass range across sizes of 387-396 g. In addition, a low cut shoe (Nike Vapor pro low TD) which features a 16 cleat outsole and a mass range of 285-296 g across sizes was considered. Both footwear were available in sizes 8-10 UK. Each participant performed the run, cut and jump movements in both footwear conditions. 
Effects of Footwear Variations on 3D Kinematics and Tibial Accelerations

\subsection{Data processing}

Trials were processed in Qualisys Track Manager in order to identify anatomical and tracking markers and were then exported as C3D files. Kinematic parameters were quantified using Visual 3D (C-Motion Inc, Gaithersburg, USA) after marker data were smoothed using a low-pass Butterworth fourth-order zero-lag filter at a cut off frequency of $12 \mathrm{~Hz} .{ }^{16}$ Kinematics of the hip, knee, ankle and tibial segment were quantified. Segmental rotations were calculated using an $X Y Z$ cardan sequence of rotations ( $X=$ sagittal plane; $Y=$ coronal plane and $Z=$ transverse plane). All data were normalized to $100 \%$ of the stance (run and cut movements) and impact phases (jump movement) of the examined movements. 3D kinematic measures from the hip, knee, ankle and tibia that were extracted for statistical analysis were (1) angle at footstrike, (2) peak angle during stance and (3) relative range of motion (ROM) from footstrike to peak angle.

The acceleration signal was filtered using a $60 \mathrm{~Hz}$ Butterworth zero-lag fourthorder low pass filter to prevent any resonance effects on the acceleration signal. ${ }^{17}$ Peak tibial acceleration was defined as the highest positive acceleration peak measured during each movement. Jump height during the vertical jump trials was also quantified using the technique adopted by Read and Cisar, ${ }^{28}$ via the vertical rise of the iliac crest marker. The vertical height rise of the iliac crest was determined as the difference between iliac crest during the standing static trial and the height attained at the peak of the flight phase.

\subsection{Statistical analysis}

Descriptive statistics (means and standard deviations) were obtained for each footwear and movement condition. Shapiro-Wilk tests were used to screen the data for normality. Depending on whether the data exhibited a normal distribution, footwear mediated differences in 3D kinematic and tibial acceleration parameters from each movement were examined using either repeated measures or Friedman's ANOVA. Statistical significance was accepted at the $p<0.05$ level. ${ }^{29}$ Effect sizes were calculated using partial $\mathrm{Eta}^{2}\left(\mathrm{p} \eta^{2}\right)$. All statistical actions were conducted using SPSS v22.0 (SPSS Inc, Chicago, USA).

\section{Results}

\subsection{Run}

Tables 1 and 2 present the discrete 3D kinematic information obtained during running as a function of footwear. Figures 1 and 2 show the 3D kinematic curves during the stance phase as a function of footwear.

\subsubsection{Tibial accelerations}

Peak tibial accelerations were significantly $\left(F_{(11)}=12.59, p<0.05, \mathrm{p} \eta^{2}=0.53\right)$ lower in the high $(6.81 \pm 2.51 \mathrm{~g})$ compared to the low cut footwear $(9.73 \pm 3.33 \mathrm{~g})$. 


\section{J. Sinclair et al.}

\begin{tabular}{|c|c|c|c|c|c|c|c|}
\hline $\begin{array}{l}1 \\
2\end{array}$ & & & & ही & 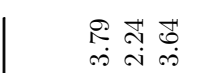 & 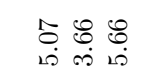 & 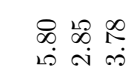 \\
\hline 3 & & & 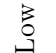 & $\exists$ & से పా & 구 $\mathcal{0} \infty$ & $\dddot{2} \Re$ \\
\hline 4 & & 0 & & 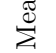 & $\sim \stackrel{\sim}{\sim}$ & & $\stackrel{100}{1}$ \\
\hline 5 & & 竝 & & & & & \\
\hline 6 & & & & की & 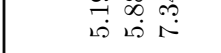 & 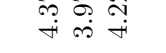 & 0 \\
\hline 7 & & & $\stackrel{.00}{.00}$ & ซ & \& & $\begin{array}{lll}\infty & \infty \\
\infty & \infty\end{array}$ & ㅇำ \\
\hline 8 & & & & 焉 & $\dot{\mathrm{S}} \overrightarrow{\mathrm{N}} \stackrel{\mathrm{N}}{\mathrm{N}}$ & $\dot{\varphi} \dot{\varphi}$ & iri \\
\hline 10 & $\stackrel{\infty}{g}$ & & & 요 & 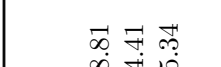 & 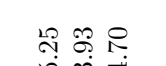 & $\stackrel{\infty}{\rightarrow} \stackrel{\infty}{\leftrightarrow}$ \\
\hline 11 & $\underbrace{5}_{0}$ & & s & & & & $\begin{array}{lll}\infty & 100 \\
0 & -1\end{array}$ \\
\hline 12 & 苛 & & • & ฮ్ర్త్ర్ & 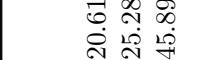 & 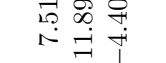 & 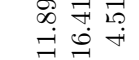 \\
\hline 13 & \pm & $\Xi$ & & & & & \\
\hline 14 & .ี & : & & 0 & 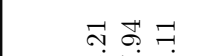 & $\exists ळ \Rightarrow$ & పా \\
\hline 15 & $\frac{\pi}{5}$ & & $\frac{-1}{50}$ & & 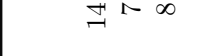 & & $\sigma 10 \infty$ \\
\hline 16 & $\vec{z}$ & & 浔 & ฮี & $\begin{array}{lll}20 \\
0\end{array}$ & 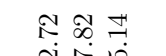 & $\stackrel{\infty}{\infty} \underset{\varnothing}{\infty}=$ \\
\hline $\begin{array}{l}17 \\
18\end{array}$ & 胥 & & & $\bar{\Sigma}$ & 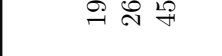 & 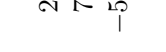 & $\uparrow=\infty$ \\
\hline 19 & $\begin{array}{l}\vec{v} \\
+\end{array}$ & & & 8 & กิ & \& 눙 : & 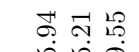 \\
\hline 20 & 焉 & & 芯 & & $=0$ & $\infty \infty$ & \\
\hline 21 & $\underbrace{\mathscr{g}}_{n}$ & & 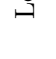 & 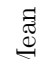 & 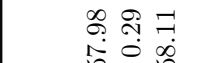 & F: 융 苞 & 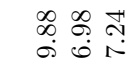 \\
\hline 22 & : & $\approx$ & & & & & \\
\hline 23 & हृ & & & 8 & 芯 & $\exists \infty \stackrel{9}{7}$ & 苛资 \\
\hline 24 & 跑 & & $\frac{\pi}{60}$ & & & & $=F$ \\
\hline 25 & : & & 毒 & สี & 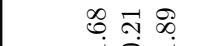 & 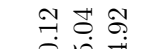 & శ్ণి \\
\hline 26 & $\stackrel{\Xi}{ \pm}$ & & & 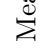 & $\overrightarrow{10} 0 \overrightarrow{010}$ & & $\dot{0}=\dot{ت}$ \\
\hline 27 & สี & & & & & & \\
\hline 28 & चี & & & & & छั & \\
\hline 29 & $\underset{\Xi}{\mathscr{Z}}$ & & & & & ઁّ & \\
\hline 30 & & & & & & है & \\
\hline 31 & 洁 & & & & & 吾 & \\
\hline 32 & $\dot{-}$ & & & & & $\approx$ & \\
\hline 33 & $\frac{0}{0}$ & & & & & $\|$ & \\
\hline 34 & & & & & & & \\
\hline 35 & & & & & ङूँ & & $\sigma$ \\
\hline $\begin{array}{l}36 \\
37\end{array}$ & & & & & 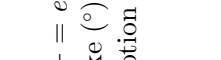 & & II \\
\hline 38 & & & & & 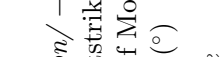 & & $\begin{array}{l}100 \\
0\end{array}$ \\
\hline 39 & & & & & 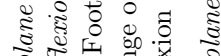 & 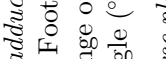 & 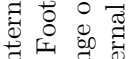 \\
\hline 40 & & & & & 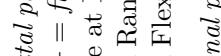 & 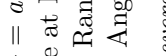 & 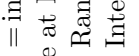 \\
\hline $\begin{array}{l}41 \\
42\end{array}$ & & & & & 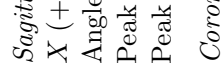 & & \\
\hline
\end{tabular}


Effects of Footwear Variations on 3D Kinematics and Tibial Accelerations

Table 2. Tibial internal rotation (means \pm standard deviation) during running.

\begin{tabular}{lrrrrr}
\hline & \multicolumn{4}{c}{ Tibia } \\
\cline { 2 - 3 } & \multicolumn{2}{c}{ High } & & \multicolumn{2}{c}{ Low } \\
\cline { 2 - 3 } \cline { 6 - 7 } & Mean & SD & & Mean & SD \\
\hline Transverse plane & & & & \\
$Z i(+=$ internal $-=$ external $)$ & & & & \\
Angle at Footstrike $\left(^{\circ}\right)$ & 8.04 & 5.45 & & 10.35 & 5.78 \\
Peak Range of Motion $\left(^{\circ}\right)$ & 7.35 & 3.65 & & 6.70 & 2.44 \\
Peak Internal Rotation $\left({ }^{\circ}\right)$ & 13.39 & 5.77 & 16.54 & 5.66 \\
\hline
\end{tabular}

\subsubsection{D Kinematics}

Peak eversion was shown to be significantly $\left(F_{(11)}=11.22, p<0.05, \mathrm{p} \eta^{2}=0.48\right)$ larger in the low cut compared to the high top footwear. In addition, peak tibial internal rotation was significantly $\left(X_{(1)}^{2}=10.65, p<0.05, \mathrm{p} \eta^{2}=0.42\right)$ greater in

Hip

Knee

Ankle

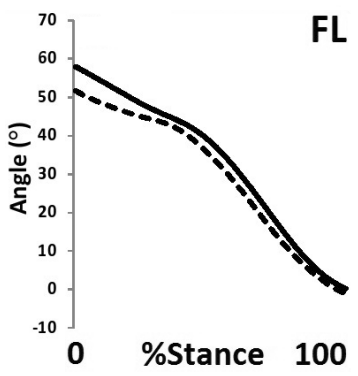

FL

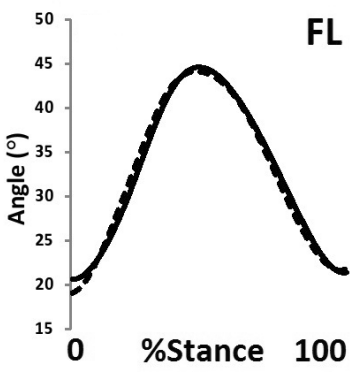

FL

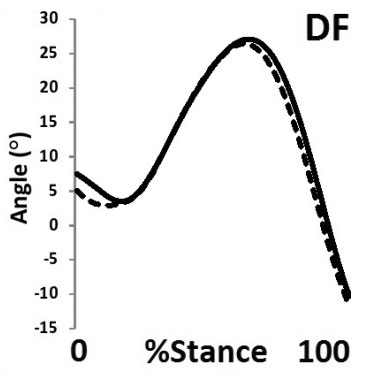

(a)
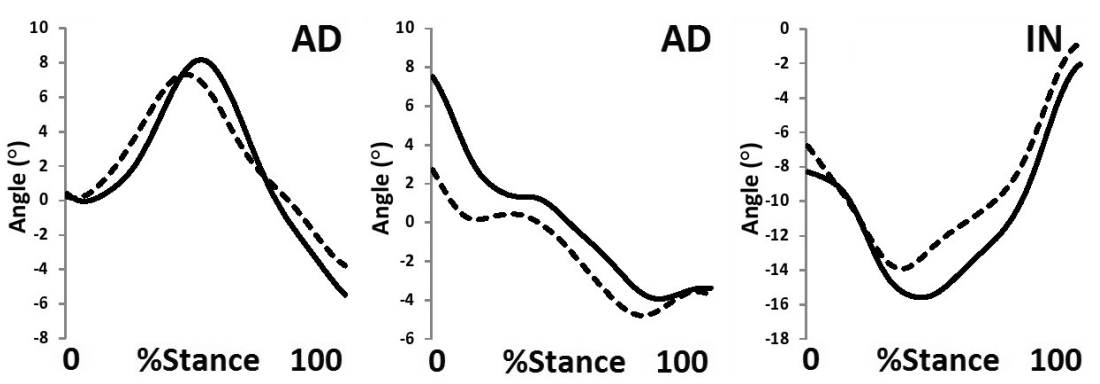

(b)

Fig. 1. Hip, knee and ankle joint angles measured during running in the (a) sagittal, (b) coronal and (c) transverse planes (black $=$ low, dash $=$ high $)(\mathrm{FL}=$ flexion, $\mathrm{DF}=$ dorsiflexion, $\mathrm{AD}=$ adduction, $\mathrm{IN}=$ inversion, INT =internal, EXT = external). 


\section{J. Sinclair et al.}
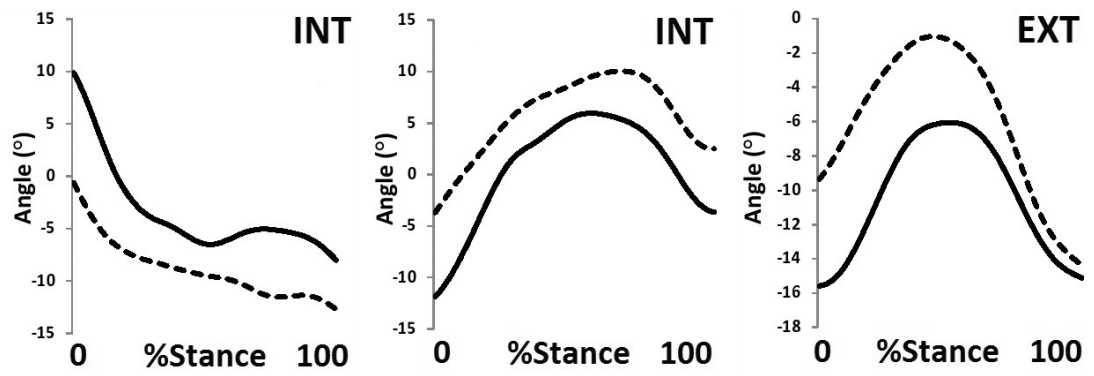

(c)

Fig. 1. (Continued)

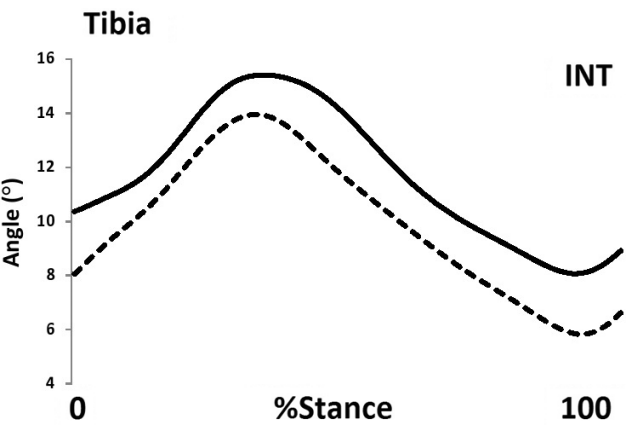

Fig. 2. Tibial internal rotation measured during running $($ black $=$ low, dash $=$ high $)($ INT $=$ internal $)$.

the low compared to the high top footwear. Peak ankle external rotation was shown to be significantly $\left(F_{(11)}=9.88, p<0.05, \mathrm{p} \eta^{2}=0.40\right)$ greater in the high top footwear compared to the low cut condition (Figs. 1 and 2 and Tables 1 and 2).

\subsection{Cut}

Table 3 presents the discrete 3D kinematic information obtained during the cut movement as a function of footwear. Figure 3 shows the 3D kinematic curves during the stance phase as a function of footwear.

\subsubsection{Tibial accelerations}

Peak tibial accelerations were significantly $\left(X_{(1)}^{2}=24.88, p<0.05, p \eta^{2}=0.69\right)$ lower in the high $(8.32 \pm 2.14 \mathrm{~g})$ compared to the low cut footwear $(12.49 \pm 2.89 \mathrm{~g})$.

\subsubsection{D Kinematics}

Peak eversion was shown to be significantly $\left(F_{(11)}=9.45, p<0.05, \mathrm{p} \eta^{2}=0.39\right)$ larger in the low compared to the high top footwear (Fig. 3 and Table 3 ). 
Effects of Footwear Variations on 3D Kinematics and Tibial Accelerations

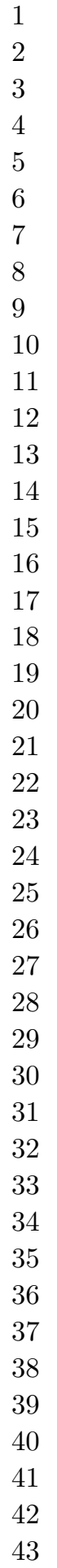

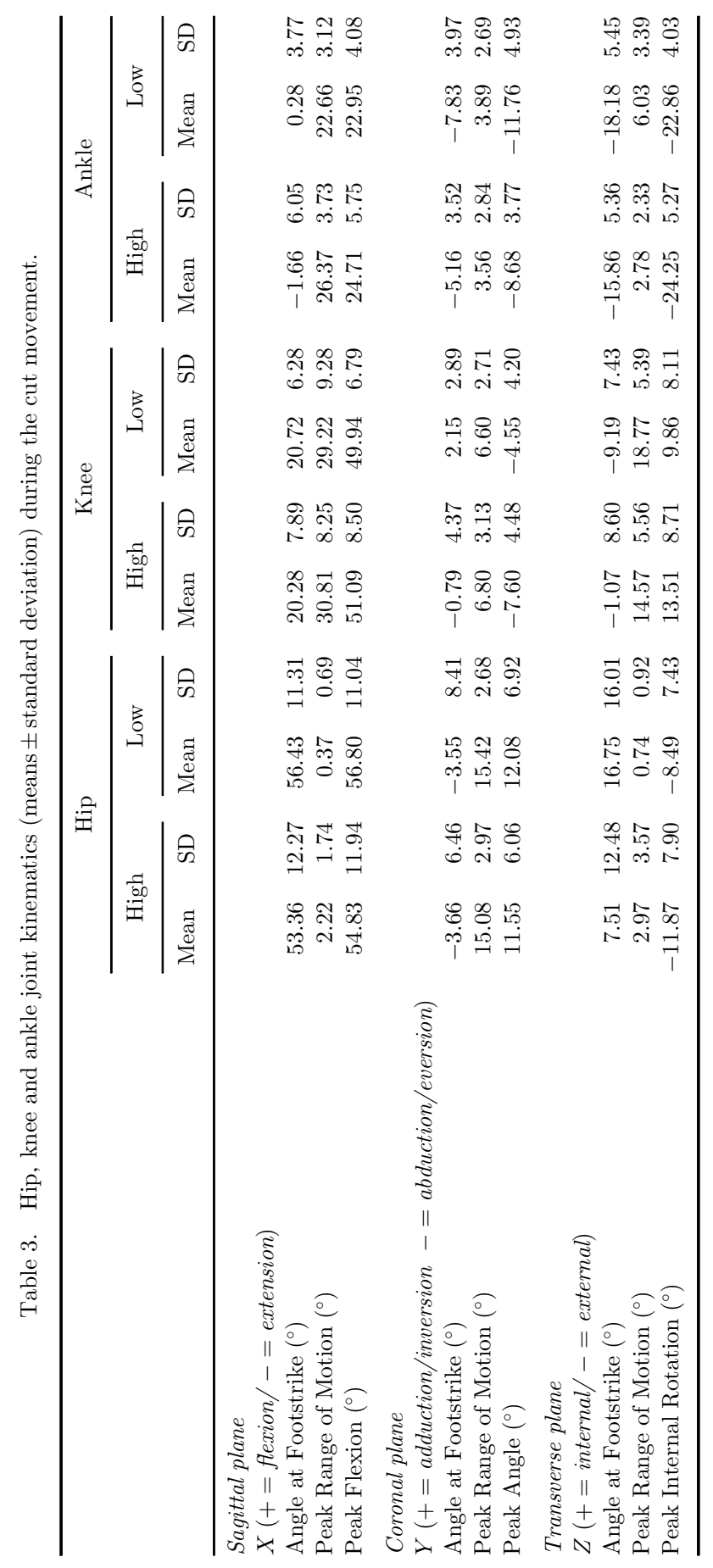

43 


\section{J. Sinclair et al.}

Hip

Knee Ankle

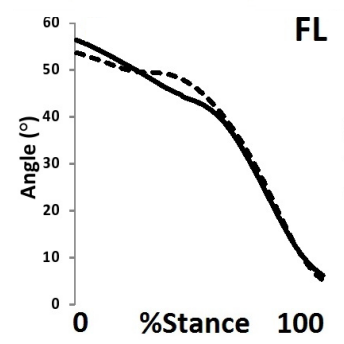

FL

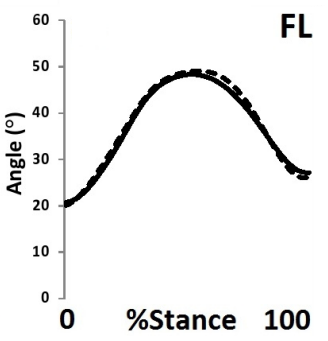

(a)
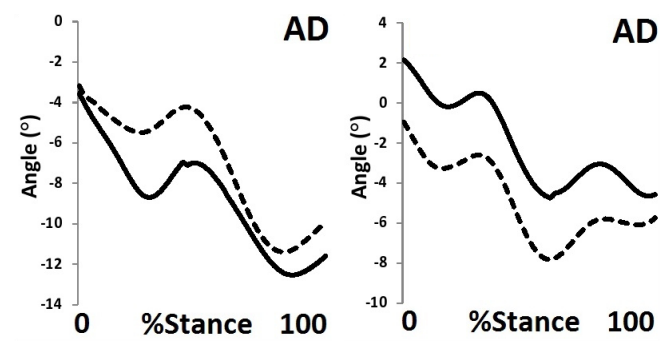

AD

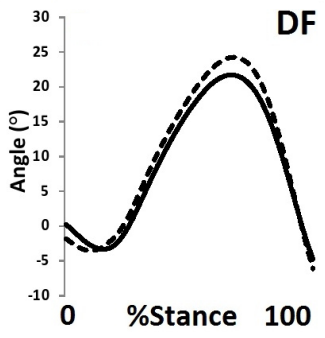

(b)
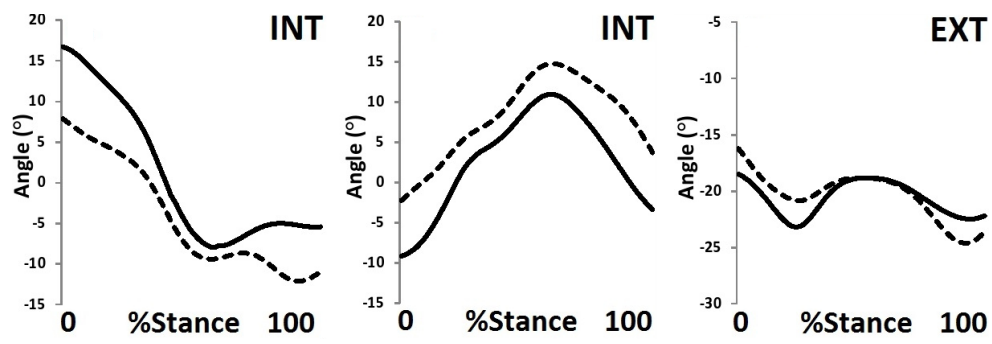

(c)

Fig. 3. Hip, knee and ankle joint angles measured during the cut movement in the (a) sagittal, (b) coronal and (c) transverse planes $($ black $=$ low, dash $=$ high $)(\mathrm{FL}=$ flexion, $\mathrm{DF}=$ dorsiflexion, $\mathrm{AD}=$ adduction, $\mathrm{IN}=$ inversion, $\mathrm{INT}=$ internal, $\mathrm{EXT}=$ external).

\subsection{Vertical jump}

Table 4 presents the discrete 3D kinematic information obtained during the jump movement as a function of footwear. Figure 4 shows the 3D kinematic curves during the impact phase as a function of footwear.

\subsubsection{Tibial accelerations and jump height}

No significant differences $(p>0.05)$ were found between the two footwear for tibial accelerations (high $=10.45 \pm 3.28 \mathrm{~g}$ and low $=11.92 \pm 3.31 \mathrm{~g}$ ) or jump height (high $=0.32 \pm 0.04 \mathrm{~m}$ and low $=0.32 \pm 0.04 \mathrm{~m})$. 
1

2

3

4

5

6

7

8

9

10

11

12 


\section{J. Sinclair et al.}

Hip
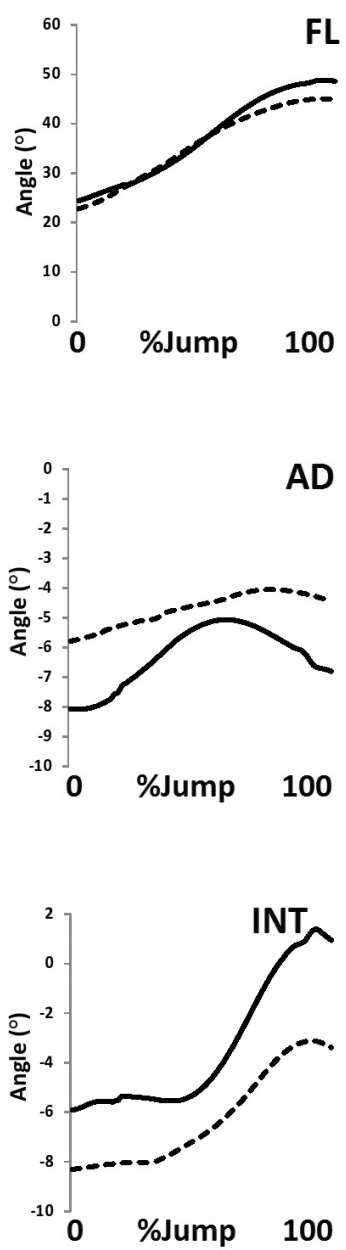

Knee

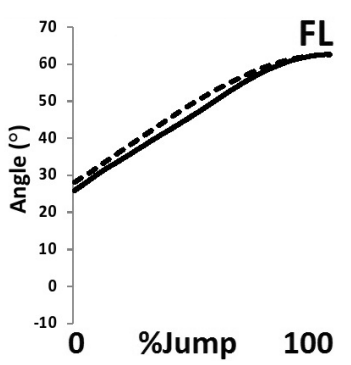

(a)
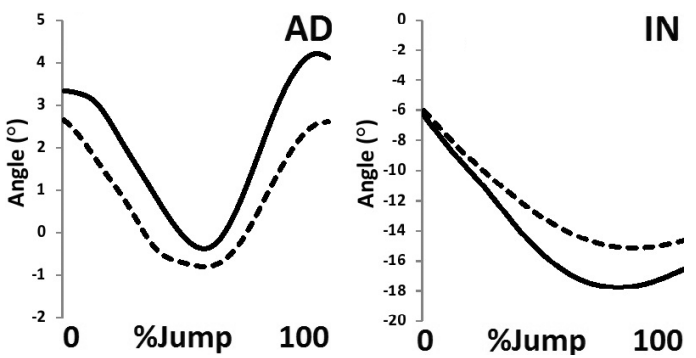

(b)
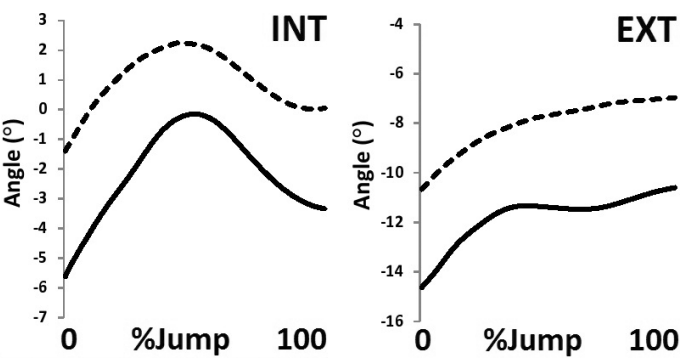

(c)

\section{Ankle}

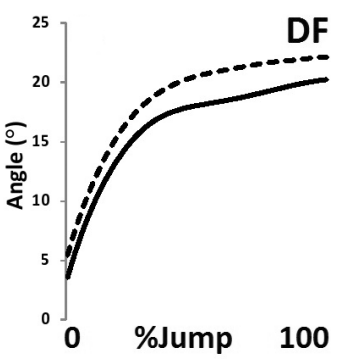

IN

Fig. 4. Hip, knee and ankle joint angles measured during the vertical jump in the (a) sagittal, (b) coronal and (c) transverse planes (black = low, dash $=$ high) $(\mathrm{FL}=$ flexion, $\mathrm{DF}=$ dorsiflexion, $\mathrm{AD}=$ adduction, IN = inversion, INT = internal, EXT = external).

\subsubsection{D Kinematics}

No significant differences $(p>0.05)$ were found between footwear (Fig. 4 and Table 4).

\section{Discussion}

This study aimed to examine the influence of high and low cut American football specific footwear on the $3 \mathrm{D}$ kinematics and tibial accelerations of three sport specific 
movements. This represents the first comparative analysis of high and low cut footwear on the 3D kinematics and tibial accelerations of American football specific movements.

The important finding from the current investigation is that the low cut footwear were associated with significant increases in tibial accelerations for both the running and cutting movements. Given the positive association between the magnitude of transient accelerations and the development of degenerative chronic pathologies, ${ }^{30}$ this observation may have clinical relevance for the pathogenesis of impact related injuries. Therefore, based on the analysis of tibial accelerations it appears that the low cut footwear may place American footballers at an increased risk from injuries related to excessive impacts. ${ }^{30}$ It is proposed that this finding relates to the additional cleats that are typically associated with low cut American football footwear which serve to stiffen the midsole in these footwear. Greater stiffness leads to an increase in the rate at which foot decelerates upon landing, increasing the magnitude of the impact transient associated with footstrike. ${ }^{30}$

A further important finding from this study is that the low cut footwear were associated with significantly larger peak ankle joint eversion and tibial internal rotation parameters in relation to the high top footwear during the running and cutting movements. This observation may have further relevance clinically as increases in eversion/tibial internal rotation have been associated with the aetiology of a number of chronic pathologies. ${ }^{31,32}$ This also suggests that when performing running and cutting movements' American football players who wear low cut footwear are more susceptible to chronic injuries relating to excessive motions of the ankle and tibia in the coronal and transverse planes. It is proposed that this finding may be caused by the high cut nature of these footwear which provide a much more pronounced medial support mechanism when contrasted against the low cut footwear. This observation is in agreement with the findings in relation to tibial acceleration in that low cut footwear may facilitate an increase in chronic injury aetiology related to excessive ankle eversion and tibial internal rotation parameters.

The current investigation also confirms that there were no differences between high and low cut footwear for the vertical jump. This concurs with the findings of Sinclair et al. ${ }^{16}$ who also showed no kinematic differences between footwear when examining this movement. It is proposed that this observation related to the fact that vertical jumping is a more explosive movement than either running or cutting, ${ }^{33}$ thus the perceptual effects of the footwear on lower extremity movement are vastly reduced. During running and cutting, the body receives feedback from mechanoreceptors concerning the movement, allowing kinematic adaptations to be made in response to external factors such as footwear. ${ }^{34}$ During singular explosive movements like the vertical jump there is no opportunity for kinematic alterations to be mediated by the external environment, thus there were no footwear effects for this motion.

A limitation to the current investigation is that it utilized an all-male sample. Although American football is played predominantly by males, both amateur and 


\section{J. Sinclair et al.}

professional female participation has expanded considerably in recent years. ${ }^{25}$ Females are known to be associated with distinct loading mechanics and lower body kinematics in comparison to age matched males and thus it is unlikely that the findings from the current investigation can be generalized to females. ${ }^{36,37}$ It is recommended that the current investigation to be repeated using a female sample in order to determine appropriate footwear characteristics for female American football players.

A further potential drawback of the current study is that the running and cutting movements were not performed at velocities that are representative of American football performance. ${ }^{38}$ Therefore, differences between the different footwear at game specific velocities were not extrapolated from this investigation. This was necessary due to the laboratory-based nature of the current work. Nonetheless, future biomechanical research may wish to examine the mechanics of running and cutting at velocities more replicable of American football performance in order to improve ecological validity.

In conclusion, the current investigation adds to the current knowledge in the area of American football biomechanics by providing a comprehensive evaluation of the $3 \mathrm{D}$ kinematics and tibial accelerations of movement in high and low cut footwear during three sport specific movements. The significant increases in both impact loading and rearfoot eversion for the running and cutting movements in the low cut footwear indicates this type of shoe may place American footballers at an increased risk from the mechanisms linked to the development of chronic injuries. The current study concludes that it may be prudent for American footballers to utilize high cut footwear for their training/performance needs.

\section{References}

1. Wannop JW, Luo G, Stefanyshyn DJ, Footwear traction and lower extremity noncontact injury, Med Sci Sports Exerc 45:2137-2143, 2013.

2. Fernandez WG, Yard EE, Comstock RD, Epidemiology of lower extremity injuries among U.S. high school athletes, Acad Med 14:641-645, 2007.

3. Nelson AJ, Collins CL, Yard EE, Fields SK, Comstock RD, Ankle injuries among United States high school sports athletes, 2005-2006, J Athl Train 42:381-387, 2007.

4. Fong DTP, Hong Y, Chan L-K, Yung PS, Chan KM, A systematic review on ankle injury and ankle sprain in sports, Sports Med 37:73-94, 2007.

5. Turbeville SD, Cowan LD, Owen WL, Asal NR, Anderson MA, Risk factors for injury in high school football players, Am J Sports Med 31:974-980, 2003.

6. Iacovelli JN, Yang J, Thomas G, Wu H, Schiltz T, Foster DT, The effect of field condition and shoe type on lower extremity injuries in American Football, $\mathrm{Br} J$ Sports Med 47:789-793, 2013.

7. Ekstrand J, Timpka T, Hagglund M, Risk of injury in elite football played on artificial turf versus national grass: A prospective two-cohort study, Br J Sports Med 40:975-980, 2006.

8. Meyers MC, Incidence, mechanisms, and severity of game-related college football injuries on Field-Turf versus natural grass: A 3 year prospective study, Am J Sports Med 38:687-697, 2010. 
9. Hershman EB, Anderson R, Bergfeld JA, Bradley JP, Coughlin MJ, Johnson RJ, Tucker A, An analysis of specific lower extremity injury rates on grass and Field Turf playing surfaces in National Football League Games: 2000-2009 Seasons, Am J Sports Med 40:2200-2205, 2012.

10. Dragoo JL, Braun HJ, Harris AHS, The effect of playing surface on the incidence of ACL injuries in National Collegiate Athletic Association American Football, Knee 20:191195, 2013.

11. Lambson RB, Barnhill BS, Higgins RW, Football cleat design and its effect on anterior cruciate ligament injuries a three-year prospective study, Am J Sports Med 24:155-159, 1996.

12. Faganel PP, Drake TC, Dahl-Miller AR, Senchina DS, Height variation in football shoes (cleats) for running backs and receivers may not alter ankle spatting effects in football field drills, J Undergrad Res 4:6-10, 2013.

13. Ricard MD, Schulties SS, Saret JJ, Effects of high-top and low-top shoes on ankle inversion, J Athl Train 35:38-43, 2000.

14. Barrett JR, Tanji JL, Drake C, Fuller D, Kawasaki RI, Fenton RM, High versus low-top shoes for the prevention of ankle sprains in basketball players. A prospective randomized study, Am J Sports Med 21:582-585, 1992.

15. Fu W, Fang Y, Liu Y, Hou J, The effect of high-top and low-top shoes on ankle inversion kinematics and muscle activation in landing on a tilted surface, J Foot Ankle Res 7:14$24,2014$.

16. Sinclair J, Chockalingam N, Naemi R, Vincent H, The effects of sport-specific and minimalist footwear on the kinetics and kinematics of three netball-specific movements, Footwear Sci 7:31-36, 2015.

17. Sinclair J, Bottoms L, Taylor K, Greenhalgh A, Tibial shock measured during the fencing lunge: The influence of footwear, Sports Biomech 9:65-71, 2010.

18. Lafortune MA, Hennig EM, Contribution of angular motion and gravity to tibial acceleration, Med Sci Sports Exerc 23:360-363, 1991.

19. Cappozzo A, Catani F, Leardini A, Benedeti MG, Della CU, Position and orientation in space of bones during movement: Anatomical frame definition and determination, Clin Biomech 10:171-178, 1995.

20. Sinclair J, Taylor PJ, Edmundson CJ, Brooks D, Hobbs SJ, Influence of the helical and six available Cardan sequences on $3 \mathrm{D}$ ankle joint kinematic parameters, Sp Biomech 11:430-437, 2013.

21. Sinclair J, Hebron J, Taylor PJ, The test-retest reliability of knee joint center location techniques, J App Biomech 31:117-121, 2015.

22. Sinclair J, Taylor PJ, Currigan G, Hobbs SJ, The test-retest reliability of three different hip joint center location techniques, Movement Sport Sci 83:31-39, 2014.

23. Graydon R, Fewtrell D, Atkins S, Sinclair J, The test-retest reliability of different ankle joint center location techniques, FAOJ (In press).

24. Cappozzo A, Cappello A, Croce UD, Pensalfini F, Surface-marker cluster design criteria for 3-D bone movement reconstruction, IEEE Trans Biomed Eng 44:1165-1174, 1997.

25. Sinclair J, Hobbs SJ, Edmundson CJ, Brooks D, Evaluation of kinematic methods of identifying foot strike and toe-off during running, Int J Sp Sci Eng 5:188-192, 2011.

26. McLean SG, Huang X, Su A, Van Den Bogert AJ, Sagittal plane biomechanics cannot injure the ACL during sidestep cutting, Clin Biomech 19:828-838, 2004.

27. Flanagan EP, Ebben W, Jensen RL, Reliability of the reactive strength index and time to stabilization during depth jumps, J Strength Condit Res 22:1677-1682, 2008.

28. Read MM, Cisar C, The influence of varied rest interval lengths on drop jump performance, J Strength Condit Res 15:279-283, 2001. 


\section{J. Sinclair et al.}

29. Sinclair J, Taylor PJ, Hobbs SJ, Alpha level adjustments for multiple dependent variable analyses and their applicability - A review, Int J Sport Sci Eng 7:17-20, 2013.

30. Whittle MW, The generation and attenuation of transient forces beneath the foot; a review, Gait Posture 10:264-275, 1999.

31. Taunton JE, Clement DB, McNicol K, Plantar fasciitis in runners, Can J Appl Sport Sci 7:41-44, 1982.

32. Eslami M, Begon M, Farahpour N, Allard P, Forefoot rearfoot coupling patterns and tibial internal rotation during stance phase of barefoot versus shod running, Clin Biomech 22:74-80, 2007.

33. Markovic G, Does plyometric training improve vertical jump height? A meta-analytical review, Br J Sports Med 41:349-355, 2007.

34. Pearson KG, Proprioceptive regulation of locomotion, Curr Opin Neurobiol 5:786-791, 1995.

35. Ezechieli M, Berger S, Siebert CH, Miltner O, Injury rates of the German Women's American Football National Team from 2009 to 2011, Orthop Rev 4:124-127, 2012.

36. Ferber R, McClay DI, Williams III DS, Gender differences in lower extremity mechanics during running, Clin Biomech 18:350-357, 2003.

37. Sinclair J, Greenhalgh A, Edmundson CJ, Brooks D, Hobbs SJ, Gender differences in the kinetics and kinematics of distance running: Implications for footwear design, Int $J$ Sp Sci Eng 6:118-128, 2012.

38. Black W, Roundy E, Comparisons of size, strength, speed and power in NCAA division I-A football players, J Strength Condit Res 8:80-85, 1994.

AQ: Reference 35 is not
cited in text. Please
check.

